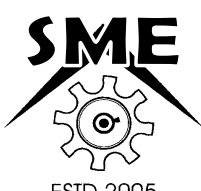

ESTD 2005

\section{ANALYSIS ON MACHINABILITY OF GFRP COMPOSITE MATERIALS USING TURNING PROCESSES}

\author{
* Rajmohan D
}

Department of Mechanical Engineering, AS-SALAM College of Engineering and Technology, Thanjavur, Tamil Nadu-612 102, India

\begin{abstract}
Glass fibre reinforced polymer (GFRP) composite materials replace traditional engineering materials due to their properties. Accordingly, the need for accurate machining of composites has increased enormously. The advantages include high strength to weight ratio, high fracture toughness and excellent corrosion and thermal resistance. Even though the moulding process may produce GFRP parts, they require further machining to facilitate dimensional control for easy assembly and control of surface quality for functional aspects. The material removal mechanism is different from that of machining single-phase materials, such as metals. GFRP are extremely abrasive when machined. Thus, selecting the cutting tool and the cutting parameters is very important in the machining process. The machinability in turning operations of glass fiber reinforced plastics (GFRP) will be investigated by the super-hard cutting tool (PCD and Ceramic Inserts). A plan of experiments will be performed on controlled machining with cutting parameters prefixed in the workpiece.
\end{abstract}

Keywords: GFRP; PCD; Ceramic Inserts; ANOVA.

\section{Introduction}

The idea of composite materials is not a new or recent one. Nature is full of examples wherein the concept of composite material is used [1]. The coconut palm leaf, for example, is nothing but a cantilever utilising the concept of fiber reinforcement. Wood is the fibrous composites: cellulose fiber in a lignin matrix [2]. In that, the lignin matrix joins the fibers and furnishes the stiffness. Bone is yet another example of a natural composite that supports the weight of various members of the body. It consists of short and soft collagen fibers embedded in a mineral matrix called apatite [3].

Since the early 1960, there has been an increasing demand for materials that are stiffer and stronger yet lighter in the field as diverse. Glass fiber reinforced resins have been in use since the 1940s [4]. Fibre-reinforced composites have been more predominant than other composites for the simple reason that most materials are stronger and stiffer in the fibrous form than any other form [5]. Glass fiber reinforced resins are very light and strong materials, although their corrosion resistance is very high [6].

There are three different processes types: Pultrusion, Prepreg, and Filament Winding [7]. Pultrusion is used for components with continuing lengths and constant cross-sectional area. The process involves fibers being drawn into a cast in which polymer resin is continually fed [8]. As stated earlier, is a continuous process. Prepreg is short for pre-pregnated process. It is also done for continuous fiber reinforcement [9]. Feeding reinforcements on to a semicured polymer resin sheet produces it. Final cure is accomplished by the simultaneous application of heat and pressure [10] The last process is a filament winding. It is accomplished when continuous reinforcing fibers are accurately positioned in a predetermined pattern to form a hollow (usually cylindrical) shape [11]. The first pattern is Helical, that is, it winds around the cylinder and then it comes back around and crosses over the previous layer. The second is Circumferential, which as it sounds is just closely wound around the shape. And the last is Polar; this is obtained by running the fiber from one end to another [12].

\section{Methodology}

\subsection{Materials and Experimental Procedure}

In order to achieve the objective of this experimental work, FRP rods of type GFRP (unsaturated polyester matrix reinforced with $70 \%$ of glass fiber), manufactured by Hydro Extruder, and were used for tests. The mechanical properties of the GFRP rod is shown in Table 1. The experiments had been carried out in rods with $25 \mathrm{~mm}$ of diameter, manufactured by pultrution process. The plan of test was developed with the nine combinations between three values of cutting velocity and three values of feed

*Corresponding Author - E- mail: drajmohan1982@gmail.com 
rate, according Table 2. A constant dept of cut of 0.5 $\mathrm{mm}$ was used. A CNC turning centre (MICRO TOUCH) with $5 \mathrm{~kW}$ spindle power and maximum speed of 3500 rpm was used to perform the experiments.

A polycrystalline diamond tool and ceramic tools (CT3000, KC 5410) of CNMG 120408 (R) were used. The used tool geometry was as follows: clearance angle 0 , edge major tool cutting 80 and $0.8 \mathrm{~mm}$ nose radius. PCD tools are produced by sintering at high temperature and under pressure particle diamond crystals (medium grain size $=10 \mu \mathrm{m}$ ) deposited on a hard metal substrate (tungsten-carbide).

Table 1 Mechanical Properties of GFRP Used

\begin{tabular}{lcc}
\hline Property & $\begin{array}{c}\text { Test } \\
\text { method }\end{array}$ & Value \\
\hline Ultimate & ASTM & $5500-6100$ \\
Tensile & D638 & $(\mathrm{MPa})$ \\
Strength & ASTM & 2 X10 \\
Tensile & D638 & $(\mathrm{MPa})$ \\
Modulus & ASTM & $4500-5500$ \\
Compressiv & D695 & $(\mathrm{MPa})$ \\
e strength & ASTM & $50-80(\mathrm{Barcol}$ \\
Hardness & D2583 & hardness $)$ \\
Specific & ASTM & $1.9-2.1$ \\
gravity & D792 & \\
\hline
\end{tabular}

\section{Design of Experiments}

Design of experiments (DOE) is a powerful statistical technique to study the effect of multiple variables simultaneously. The DOE using Taguchi approach: an economically satisfy the needs of problem solving and product/process design) optimization projects. It offers a method of getting the maximum information from the minimum number of tests.

The Taguchi technique places a great deal of importance on the reduction in variability of products and processes; in other words, make products and processes more robust and less susceptible to changes due to outside influences such as raw material variation, temperature and changes to machines and operators. By learning and applying this technique, one can significantly reduce the time required for experimental investigations. Orthogonal Arrays are a set of tables of numbers created by Taguchi that allow experimenters to study the effect of a large number of control factors on the quality characteristics in a minimum number of trials.

\subsection{Steps involved in Taguchi Method}

i. Identify the Response function and the Process parameter to be evaluated. ii. Determine the number of levels for the process parameter and the possible interactions between them.

iii. Select the appropriate orthogonal array and assign the process parameters to the orthogonal array and conduct experiment.

iv. Calculate the loss function and the $\mathrm{S} / \mathrm{N}$ ratio.

v. Analyze the experiment results using $\mathrm{S} / \mathrm{N}$ ratio and ANOVA.

vi. Select the optimum level of process parameters.

vii. Verify the optimal process parameter through a confirmation experiment.

Table 2 Control Parameters and their Levels

\begin{tabular}{ccccc}
\hline $\begin{array}{c}\text { S. } \\
\text { No. }\end{array}$ & Parameters & Low & $\begin{array}{c}\text { Levels } \\
\text { Medium }\end{array}$ & High \\
\hline 1. & $\begin{array}{c}\text { Cutting Speed } \\
(\mathrm{rpm})\end{array}$ & 1500 & 2000 & 2500 \\
2. & Feed $(\mathrm{mm} / \mathrm{rev})$ & 0.1 & 0.2 & 0.3 \\
\hline
\end{tabular}

Nomenclature of OA: $\mathrm{L}_{\mathrm{a}}\left(\mathrm{b}^{\mathrm{c}}\right)$

$\mathrm{L}$ - Latin square - number of rows indicates the number of experiments required when using that OA.

b - Number of levels indicates that the number of factor levels.

c - Number of columns indicates the number of factors that can be studied in an OA

From DOE using Taguchi approach, orthogonal array is formed with coded factors and shown in Table 3. The orthogonal array table is presented in Table 4 with the actual levels of the factors. Once the appropriate OA has been selected, the factors can be assigned to various columns of the array.

Table 3 L9 Orthogonal Array

\begin{tabular}{ccc}
\hline Exp. No. & $\begin{array}{c}\text { Column } \\
\mathbf{1}\end{array}$ & $\begin{array}{c}\text { Column } \\
\mathbf{2}\end{array}$ \\
\hline 1 & 1 & 1 \\
2 & 1 & 2 \\
3 & 1 & 3 \\
4 & 2 & 1 \\
5 & 2 & 2 \\
6 & 2 & 3 \\
7 & 3 & 1 \\
8 & 3 & 2 \\
9 & 3 & 3 \\
\hline
\end{tabular}


Table 4 Design Matrix Used for the Tests

\begin{tabular}{ccc}
\hline Test & $\begin{array}{c}\text { Speed } \\
(\mathbf{m} / \mathbf{m i n})\end{array}$ & $\begin{array}{c}\text { Feed } \\
(\mathbf{m m} / \mathbf{r e v})\end{array}$ \\
\hline 1 & 50 & 0.05 \\
2 & 50 & 0.1 \\
3 & 50 & 0.2 \\
4 & 100 & 0.05 \\
5 & 100 & 0.1 \\
6 & 100 & 0.2 \\
7 & 150 & 0.05 \\
8 & 150 & 0.1 \\
9 & 150 & 0.2 \\
\hline
\end{tabular}

\subsection{Determination of Machining Performance}

\section{ANOVA}

This method was developed by Sir Ronald Fisher. Analysis of Variance is a statistically Based, difference in average performance of group of items tested. ANOVA is a computation technique to estimate quantitatively the relative contribution which each controlled parameter makes on the overall measured response ad is expressed as a percentage. The decision rather than pure judgment, takes variation into account.

\section{Tool Wear}

Tool wear was measured using a passing and reflection type Toolmaker's microscope. Flank wear was measured by the wear-land on the flank below the cutting edge.

\section{Surface Roughness}

Stylus instruments are based on the principle of running a probe across a surface in order to detect variations in height as a function of distance. One of the early stylus instruments employed a system of levers to magnify the vertical displacement of the stylus and recorded the profile on a smoked-glass plate.

The next step in the development of the stylus instruments was to incorporate a transducer, which converted vertical displacement into an electrical signal. This signal can then be processed by the instrument electronics to calculate a suitable roughness parameter. The type of transducer used largely affects instrument performance. A piezoelectric crystal is often used as the transducer in the less expensive instruments.

Other transducer mechanisms include moving coil transducers, capacitance transducers and linear variable differential transformers (LVDT). Surface roughness of machined component was measured using contact stylus surface roughness tester. Ra was measured using the surf-coder roughness tester. objective decision making tool for detecting any

Roughness measuring conditions are:

Evaluation length: [Cut off -7],

Free: $8 \mathrm{~mm}$

Cut off: $0.8 \mathrm{~mm}$,

Measuring speed: $0.5 \mathrm{~mm} / \mathrm{s}$,

Vertical magnification: 10,000

Horizontal magnification: 500

\section{Sum of Squares}

The purpose of ANOVA is to investigate which of the process parameter significantly affect the performance characteristics. This is accomplished by separating the total variability of the $\mathrm{S} / \mathrm{N}$ ratios, which is measured by the squared variations from the total mean of the $\mathrm{S} / \mathrm{N}$ ratio, into the contribution by each process parameter and the error. First, the total sum of the squared deviations TSS from the total mean of the S/N ratio can be calculated by the equation.

Total sum of squares (TSS) $=\sum \eta_{\mathrm{i}}^{2}-\mathrm{CF}$

$=$ Sum of squares for all observations (SS) correction factor $(\mathrm{CF})$

Correction factor is used to correct the sum of squares of observations.

Main Factor Effects

$\mathrm{SS}_{\mathrm{A}}=\left(\sum \eta^{2}{ }_{\mathrm{Ai}} / \mathrm{N}_{\mathrm{Ai}}\right)-\mathrm{CF}$

Where,

$$
=\left(\mathrm{A}_{1}\right)^{2} / \mathrm{N}_{\mathrm{A} 1}+\left(\mathrm{A}_{2}\right)^{2} / \mathrm{N}_{\mathrm{A} 2}+\left(\mathrm{A}_{3}\right)^{2} / \mathrm{N}_{\mathrm{A} 3}-\mathrm{CF}
$$

$\mathrm{A} 1=\sum$ Observations (Where one sets Factor A at ' 1 ') $=\eta_{1}+\eta_{2}+\eta_{3}$, set at ' 1 '.

$\mathrm{N}_{\mathrm{A} 1}=$ Number of observations with factor $\mathrm{A}$

\section{Degree of Freedom (N)}

Degree of freedom is the ability to compare the levels of a factor independently. If there are $\mathrm{N}$ different levels of each parameter, then degree of freedom is given by:

DOF for factor $\left(\mathrm{DOF}_{\mathrm{f}}\right)=$ Number of levels -1

DOF тотАL $=$ Total number of observations -1

DOF for error $\left(\mathrm{DOF}_{\mathrm{e}}\right)=\mathrm{DOF}$ тотAL - Sum of DOF for factors and interactions.

\section{Variance}

Error variance or simply variance is equal to the sums of the squares of error divided by the degrees of freedom of the error parameter. Error variance is the measure of the variation due to all uncontrolled parameters, including the measurement error involved in the experiment. of freedom.

Variance $=$ Sum of squares of a factor $/$ Degree 


\section{Residual}

Error sum of squares $\left(\mathrm{SS}_{\mathrm{e}}\right)=\mathrm{TSS}-\left(\mathrm{SS}_{\mathrm{A}}+\right.$ $\left.\mathrm{SS}_{\mathrm{B}}+\mathrm{SS}_{\mathrm{C}}+\mathrm{SS}_{\mathrm{D}}\right)$

$\mathrm{SS}_{\mathrm{e}}=$ TSS - Total of sum of squares of all factors and interactions.

\section{Percentage Distribution}

The portion of the total variation observed in an experiment attributed to each factor is reflected in present contribution. The percent contribution is a function of the sum of the squares for each significant item. It indicates the relative power of a factor to reduce variation. If the factor levels were controlled precisely, then the variation could be reduced by the amount indicated be the percent contribution.

The percent contribution is given by $\% \mathrm{P}=$ Sum of square / Total sum of square

\section{Results and Discussion}

\subsection{Observed Data and Graphs}

The results of tests allowed the evaluation of two types of cutting tools used in turning of GFRP composite materials (KC5410 and CT 3000) from the point of view of machinability. The plan of tests was developed with the aim of relating the influence of the cutting velocity $(\mathrm{V})$ and the feed rate (f), with the surface roughness $(\mathrm{Ra})$ and the Tool wear in function of cutting tool (polycrystalline diamond tool and ceramic inserts). Tables $5 \& 6$ show the results of experimental values of $\mathrm{Ra}$ parameter. The evolution of the surface roughness in function of the feed rate, for several cutting velocities, can be seen in Figures $1 \& 2$. It can be evidenced that the values of Ra increases with the feed rate and decreases with the cutting velocity. It can be noticed that using polycrystalline diamond tool (PCD) smaller values of surface roughness have been obtained and produce very low flank wear compare to other ceramic inserts.

Tool wear plays an important in the evaluation of machining accuracy. Exact data for the new, advanced tools, edge performance and their life is an essential condition for their application. Although many factors affect tool wear, machining parameters such as cutting speed, feed rate depth of cut and work piece properties have a significant influence for a given machine tool and work piece set-up.

The techniques and methodologies required for processing composite materials are substantially different from those for metals. The mechanism of cutting in GFRP composites is due to the combination of plastic deformation, shearing and bending rupture. The increase in feed rate produces heat generation in between the tool and work piece which in-turn produces more tool wear.
Table 5 Experimental Test Condition and Observed Data for PCD

\begin{tabular}{ccccc}
\hline Speed & Feed & DOC & $\begin{array}{c}\text { Surface } \\
\text { Roughness }(\mu \mathrm{m})\end{array}$ & $\begin{array}{c}\text { Tool } \\
\text { Wear }(\mathbf{m m})\end{array}$ \\
$(\mathbf{r p m})$ & $(\mathbf{m m} / \mathbf{r e v})$ & $(\mathbf{m m})$ & PCD & PCD \\
\hline 1500 & 0.1 & 0.5 & 2.21 & 0.51 \\
2000 & 0.1 & 0.5 & 2.07 & 0.48 \\
2500 & 0.1 & 0.5 & 1.81 & 0.56 \\
1500 & 0.2 & 0.5 & 2.93 & 0.58 \\
2000 & 0.2 & 0.5 & 2.57 & 0.61 \\
2500 & 0.2 & 0.5 & 2.42 & 0.63 \\
1500 & 0.3 & 0.5 & 3.51 & 0.67 \\
2000 & 0.3 & 0.5 & 3.47 & 0.69 \\
2500 & 0.3 & 0.5 & 3.4 & 0.71 \\
\hline
\end{tabular}

Table 6 Experimental Test Condition and Observed Data for Ceramic

\begin{tabular}{ccccc}
\hline Speed & Feed & DOC & $\begin{array}{c}\text { Surface } \\
\text { Roughness } \\
(\boldsymbol{\mu m})\end{array}$ & $\begin{array}{c}\text { Tool } \\
\text { Wear } \\
(\mathbf{m m})\end{array}$ \\
$(\mathbf{r p m})$ & $(\mathbf{m m} / \mathbf{r e v})$ & $(\mathbf{m m})$ & $\begin{array}{c}\text { Ceramic } \\
\text { Ceramic }\end{array}$ \\
\hline 1500 & 0.1 & 0.5 & 2.23 & 0.58 \\
2000 & 0.1 & 0.5 & 2.18 & 0.52 \\
2500 & 0.1 & 0.5 & 2.12 & 0.6 \\
1500 & 0.2 & 0.5 & 3.15 & 0.63 \\
2000 & 0.2 & 0.5 & 3.08 & 0.67 \\
2500 & 0.2 & 0.5 & 3 & 0.64 \\
1500 & 0.3 & 0.5 & 3.52 & 0.65 \\
2000 & 0.3 & 0.5 & 3.18 & 0.7 \\
2500 & 0.3 & 0.5 & 2.91 & 0.71 \\
\hline
\end{tabular}


Journal of Manufacturing Engineering, December 2021, Vol. 16, Issue. 4, pp 127-134

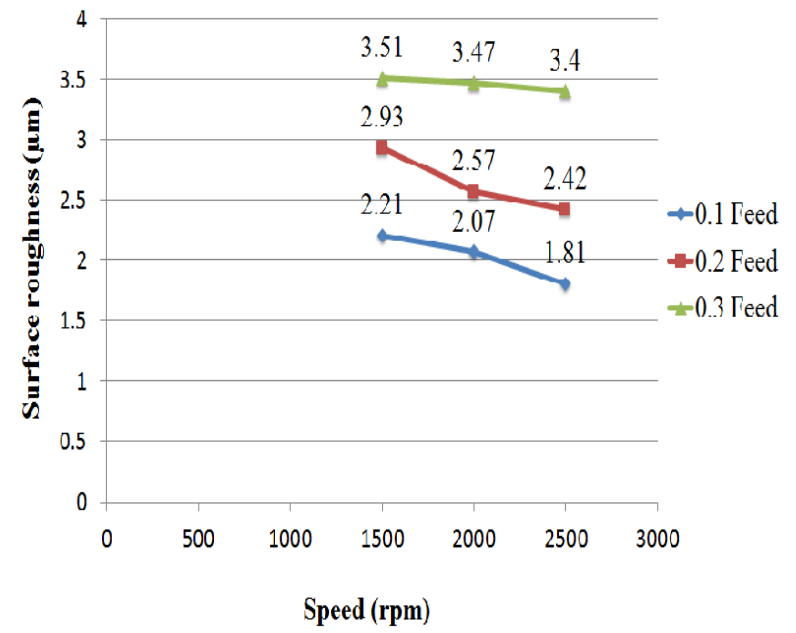

Fig. 1 Relation between Surface Roughness Vs Cutting Speed in PCD

From the Figure 1, as speed increases surface roughness decreases in PCD. Improvements of surface finish with increasing speed is narrow in the case of 0.1 feed rate but in the case of 0.3 feed rate surface roughness decreases at faster rate of $0.5 \mu \mathrm{m}$ to $0.6 \mu \mathrm{m}$. It is clearly understand that the surface roughness is decreased with increasing the cutting speed.

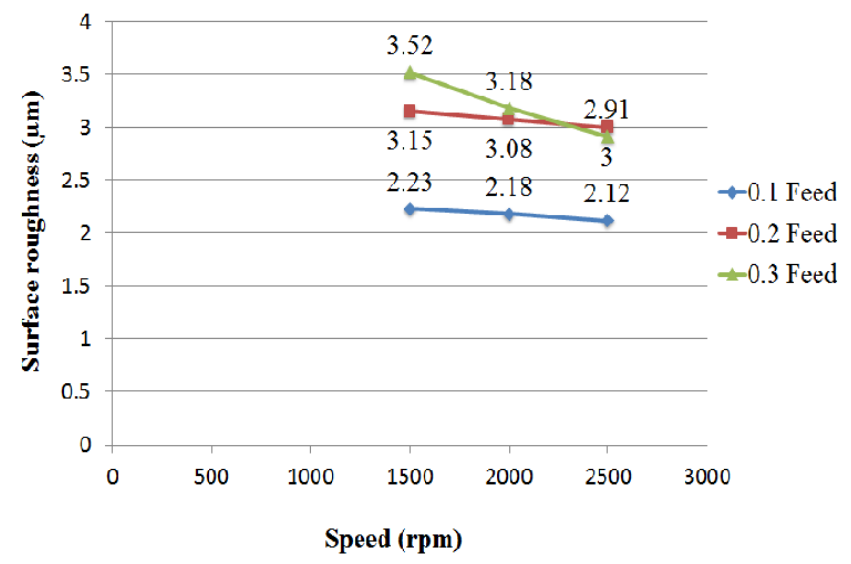

Fig. 2 Relation between Surface Roughness Vs Cutting Speed in Ceramic

From the Figure 2, as speed increases surface roughness decreases in ceramic. Improvements of surface finish with increasing speed is narrow in the case of 0.1 feed rate but in the case of 0.3 feed rate surface roughness decreases at faster rate of $0.5 \mu \mathrm{m}$ to $0.6 \mu \mathrm{m}$. It is clearly understand that the surface roughness is decreased with increasing the cutting speed.

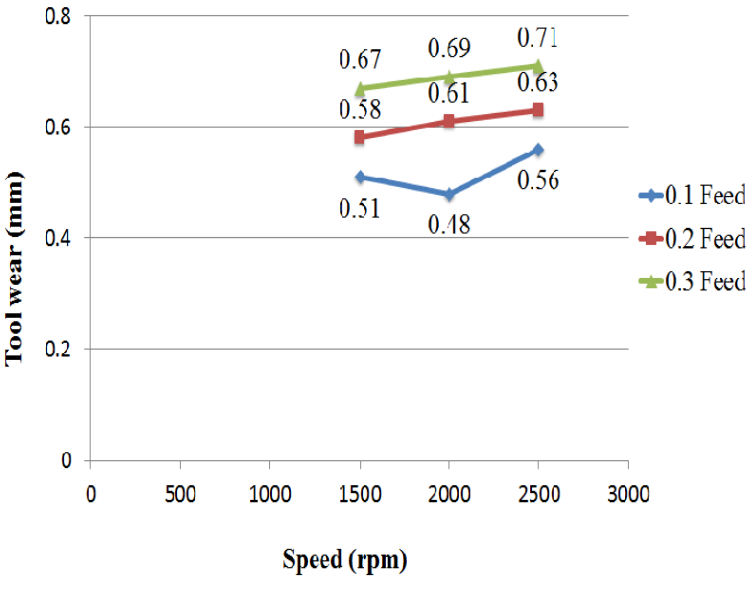

Fig. 3 Relation between Tool Wear Vs Cutting Speed in PCD

From the Figure 3, when a graph is plotted between cutting speed Vs tool wear, where speed is expressed in $\mathrm{m} / \mathrm{min}$ and tool wear is expressed in $\mathrm{mm}$. It is clearly understood that, the cutting speed increase linearly with increase in tool wear. The relationship between the tool wea and cutting speed while using ceramic cutting insert is shown in Figure 4.

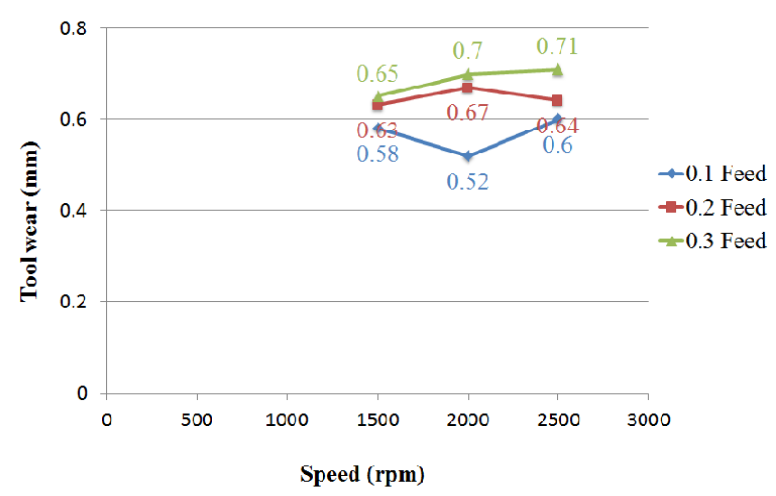

Fig. 4 Relation between Tool Wear Vs Cutting Speed in Ceramic

The experimental observations are further transformed into a signal to noise ratio, the characteristic that has lower value represents better machining performance, such as surface finish. Therefore 'LB' for the surface finish (SF) was selected for obtaining optimum machining performance characteristics. The loss function (L) for objective LB is defined as follows, where $\mathrm{Y}_{\mathrm{SF}}$ represent response for surface finish and ' $n$ ' denotes the number of 
experiments The $\mathrm{S} / \mathrm{N}$ ratio can be calculated as a logarithmic transformation of the loss function as shown below :

$\mathrm{S} / \mathrm{N}$ ration for $\mathrm{SF}=-10 \log _{10}\left(\mathrm{~L}_{\mathrm{LB}}\right)$

The obtained $\mathrm{S} / \mathrm{N}$ ratio values for the surface roughness data while machining with PCD tool is tablualted in Table 7.

Table 7 S/N Ratio Values of Surface Roughness (PCD Tool)

\begin{tabular}{cccc}
\hline Factors & \multicolumn{3}{c}{ S/N Ratio } \\
& Level 1 & Level 2 & Level 3 \\
\hline Speed & -9.288 & -8.863 & -8.449 \\
Feed & -6.754 & -9.76 & -10.086 \\
\hline
\end{tabular}

The obtained $\mathrm{S} / \mathrm{N}$ ratio values for the surface roughness data while machining with ceramic tool is tablualted in Table 8 .

Table 8 S/N Ratio Values of Surface Roughness (Ceramic Tool)

\begin{tabular}{cccc}
\hline Factors & \multicolumn{3}{c}{ S/N Ratio } \\
& Level 1 & Level 2 & Level 3 \\
\hline Speed & -9.043 & -8.441 & -7.819 \\
Feed & -6.12 & -8.404 & -10.78 \\
\hline
\end{tabular}

From the results, it was identified that the combination (Speed $-3^{\text {rd }}$ lvel $\&$ Feed $-1^{\text {st }}$ level) was the optimal combination for obtaining lesser surface roughness while machining.

\section{ANOVA Results}

Variability of process factor was analyzed using ANOVA and the results are shown in Table 9.

From the ANOVA table it is clear that Speed is the major influencing factor followed by Feed, for surface roughness. Table $4.3 \& 4.4$ shows the results of the analysis of variance with surface roughness $(\mathrm{Ra})$ in work piece. The last columns of Table $4.5 \& 4.6$ show the percentage of contribution $(\mathrm{P})$ of each factor on the total variation, indicating then the degree of influence on the result. From the analysis of this table it can be observed that the cutting velocity factor $(\mathrm{P}=3.23 \%)$ and the feed rate factor $(\mathrm{P}=93.55 \%)$ have statistical and physical significance on the surface roughness obtained.
Table 9 ANOVA Results for Ra (Ceramic)

\begin{tabular}{|c|c|c|c|c|}
\hline Factor & DOF & $\begin{array}{c}\text { Sum of } \\
\text { Squares }\end{array}$ & $\begin{array}{c}\text { Mean } \\
\text { Square }\end{array}$ & $\% \mathrm{P}^{*}$ \\
\hline Speed & 2 & 32.58 & 16.29 & 93.55 \\
\hline Feed & 2 & 2.247 & 1.123 & 3.23 \\
\hline
\end{tabular}
surface roughness, further tool wear is studied with respect to time for the entire tool and observed data's tabulated in Table 10.

\section{Table 10 Experimental test condition and observed} data for tool life

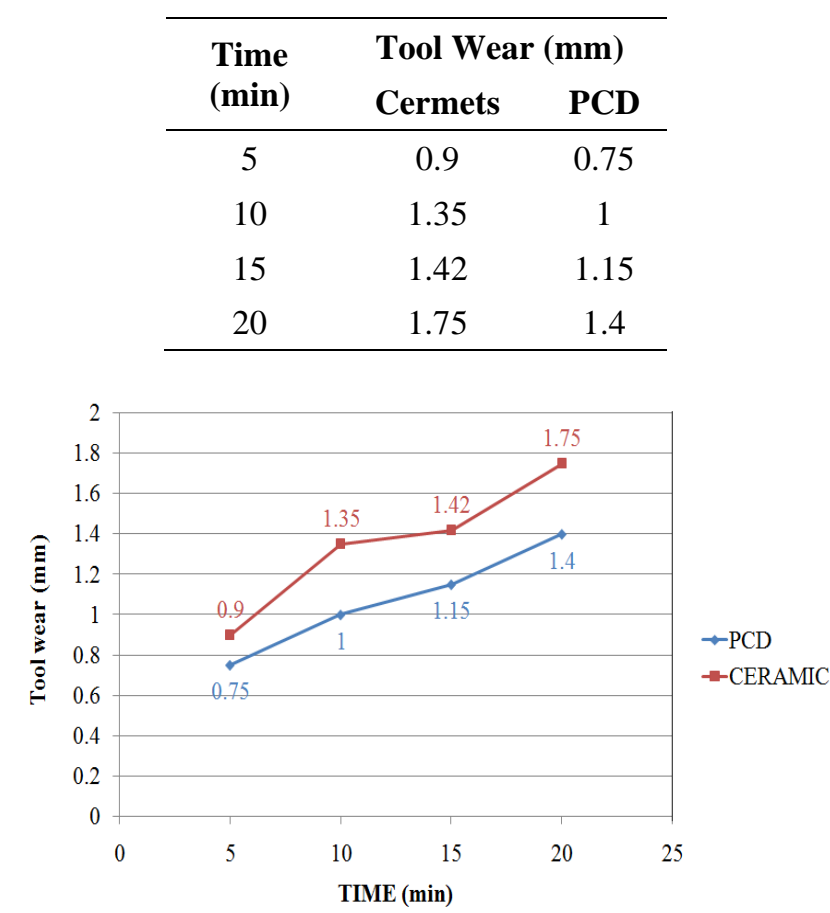

Fig. 5 Relation between Time Vs Tool wear in PCD \&Ceramic

From the Figure 5, it is clearly understood that, the tool wear increasing with the machining time. Ceramic inserts shows sharp wear during its initial and end periods. This is to wear should be maximum at the beginning due to infant periods. After that tool is in subjected to progressive wear, at the end the tool wear out at fast rate due to its failure mode. But in case of PCD we did not see the progressive wear, because PCD does not have progressive wear. 


\subsection{SEM Analysis}

SEM view of PCD insert after turning is presented in Figure 6. SEM view of PCD insert after 10 min turning is shown in Figure 7. The cutting velocity directly influences the amount of thermal energy, which is created at the cutting edge. The heat distribution between tool and work piece depends and the thermal conductivity of the material. In this system diamond reaches the higher value while the glass fibers and the polymer matrix directed towards the tool surface. Due to superior hardness and wear resistance polycrystalline diamond tool sustains the least tool wear.

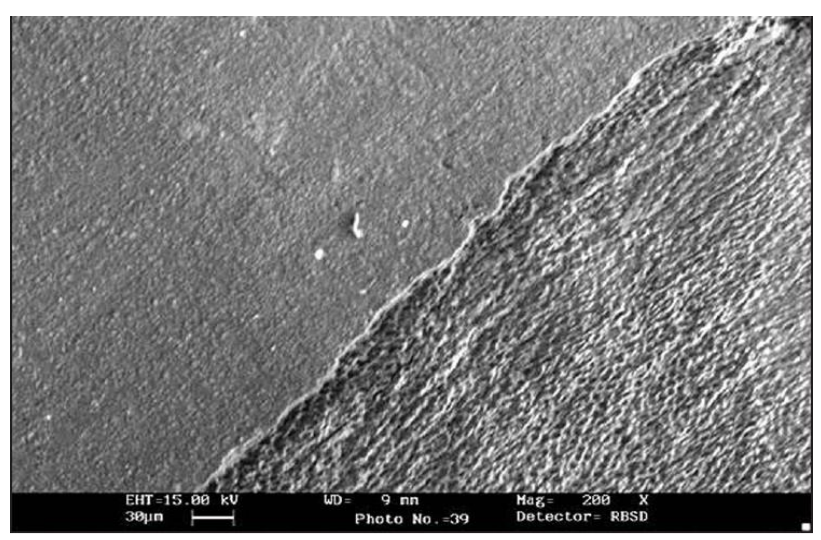

Fig. 6 SEM view of PCD insert after turning
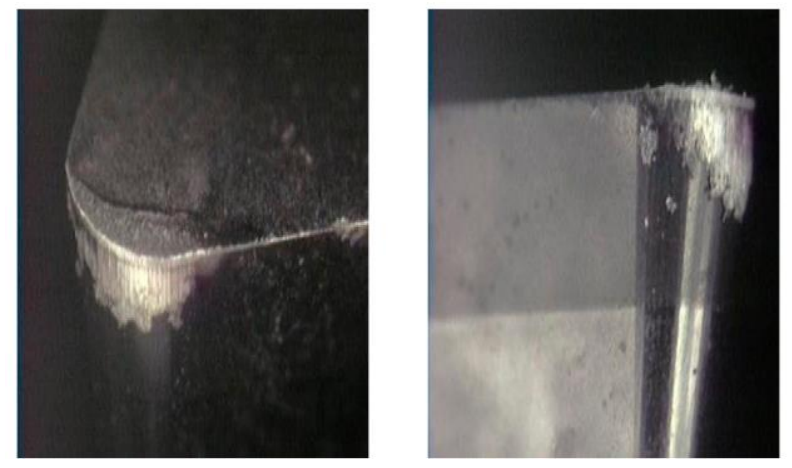

Fig. 7 SEM view of PCD insert after 10 min turning

During machining of pultruted glass fiber plastic rods, material is removed in the form of powder. This powder material sticks to the flank surface and forms build-up edge. Build-up edge is noted on the PCD inserts. Build-up edge is reduced if the machining time is increased.

On the flank side, grooved surface appears, caused primarily by the abrasive actions of the glass fiber present in the work piece. Size of the groove is increased with increasing machining time and the cutting edge gets deformed. The edge deformation is increased with increase in machining time.

SEM views showed that the machining of GFRP materials are subjected to plastic deformation, shearing and rupturing of fibers. Since the glass fibers break by rupturing and shearing at short lengths without flowing over the rake surface, as in the case of metal chips, craterization is inhibited, instead the tool edge is abraded by the hard glass fibers. The extent of tool material abraded by the glass fibers is very clearly shown in the scanning electron micrographs. The cutting edges of polycrystalline diamond insert where taken after turning the GFRP.

\section{Conclusions}

Using design of experiment, the machining parameters which are influencing the tool wear on the machining of GFRP composites has been modeled. This investigation achieves an understanding of the parameters of machinability and leads to the following.

i. Polycrystalline diamond tool (PCD) presents smaller values of surface roughness and Tool wear than ceramic inserts (CT 3000 \& KC 5410).

ii. The feed rate is the cutting parameter that has the highest physical as well statistical influence on surface roughness $(\mathrm{Ra})$ and Speed.

iii. Polycrystalline diamond tool (PCD) provides a better machinability in comparison to ceramic inserts (CT 3000 \& KC 5410). Therefore, PCD cutting tool gave the best overall performance.

iv. The effect of parameters on surface roughness is found based on analysis of variance and it concludes the following results for carbide and cermets. For carbide, feed is the major factor $(\mathrm{p}=93.35 \%)$ followed by the cutting speed $(\mathrm{p}=3.23 \%)$ for surface finish

v. For cermets, feed is the major factor $(\mathrm{p}=95 \%)$ followed by the cutting speed $(\mathrm{p}=2.5 \%)$ for surface finish.

vi. Flank wear and edge deformations are caused by the abrasive actions of the glass fiber present in the work piece.

vii. Machining of GFRP produces irritation to skin and is dangerous for health.

\section{References}

1. Aravindan S, Naveen sait A and Noorulhaq(2007) , 'A Machinabilty study of GFRP pipes using statistical technique'. International journal of Manufacturing Technology Vol 70-007-1055-3.

2. Bernardos $P G$, Vosniakos GC. Predicting surface roughness in machining: a review. Int J Mach Tools Manuf 2003; 43:833-44. 
Journal of Manufacturing Engineering, December 2021, Vol. 16, Issue. 4, pp 127-134

3. Chung-Shin Chang (2006), "turning of GFRP materials with chamfered main cutting edge carbide tools",International journal of material processing technology Vol 180 pp 117-129.

4. Davim JP, Reis P, Conceic,ãoAnto'nio C. Experimental study of drilling glass fiber reinforced plastics (GFRP) manufactured by hand lay-up. Compos SciTechnol 2004; 84:289-97.

5. Davim JP, Reis P, Lapa V, Anto nio C. Machinability study on polyetheretherketone (PEEK) unreinforced and reinforced (GF30) for applications in structural components. Compos Struct 2003; 62:67-73.

6. Davim JP, Reis P. Machinability study on composite (polyetheretherketone reinforced wit 30\% glass fibre$P E E K G F 30$ ) using polycrystalline diamond $(P C D)$ and cemented carbide (K20) tools. Int J AdvManufTechnol
ceme 2004; 23:412-8.

7. Davim JP. Diamond tool performance in machining metalmatrix composites. J Mater Process Technol 2002, 128:100-5.
8. El-Sonbaty, Khashaba UA, Machaly T. Factors affecting the machinability of GFR/epoxy composites. Comp Struck 2004; 63:329-38.

9. Groover MP. Fundamentals of modern manufacturing materials, process and systems. Prentice Hall International Editions; 1996. pp. 637-39.

10. Palanikumar K and JauloDavim J (2006), Mathematical model to predict tool wear on the machining of GFRP composites'. International journal of material and design Vol 28 pp 2008-2014.

11. Palani Kumar K, Sathyabama Institute (2006), 'Modeling and analysis for surface roughness in machining GFRP using response surface methodology'. International journal of material and design Vol 28 pp 2611-2618.

12. Rahman M, Ramakrishna S, Prakash JRS, Tan DCG. Machinability study of carbon fiber reinforced composite. Mater Process Technol1999;89-90:292-7. 